\title{
Determinant of Stress and Burnout among Nurses at the Second Wave of the Indonesian COVID-19 Pandemic: A National Web- based Survey
}

\author{
Yani Sofiani $^{1 *}$ (D) , Abdu Rahim Kamil ${ }^{1}$, Dedi Muhdiana ${ }^{4}$, Prima Trisna Aji ${ }^{2}$, Dede Kurniati ${ }^{1}$, Diwa Agus Sudrajat ${ }^{3}$ D \\ ${ }^{1}$ Department of Medical Surgical Nursing, Faculty of Nursing, Universitas Muhammadiyah Jakarta, South Tangerang, Indonesia; \\ ${ }^{2}$ Department of Medical Surgical Nursing, Fakultas IImu Kesehatan, Universitas Kusuma Husada Surakarta, Surakarta, \\ Indonesia; ${ }^{3}$ Department of Medical Surgical Nursing, Sekolah Tinggi Ilmu Keperawatan PPNI Jawa Barat, Bandung, Indonesia; \\ ${ }^{4}$ Bachelor Nursing Program, Sekolah Tinggi IImu Kesehatan Bani Saleh, Bekasi, Indonesia
}

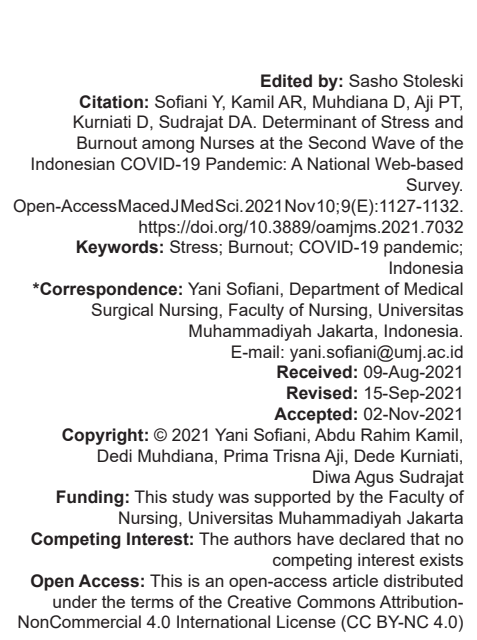

\section{Introduction}

COVID-19 pandemic has developed into a major public health threat [1]. According to the International Council of Nurses report, 90,000 health care workers were infected, and over 260 nurses died from COVID-19 [2]. Indonesia has confirmed the case of COVID-19 for the $1^{\text {st }}$ time in early March 2020. Since then, the number of confirmed cases has continued to rise, to date. In Indonesia, there were 1.29 million confirmed cases, 1.1 million recovered, and 34,691 deaths [3]. The government has made numerous efforts to limit the number of incidents, with management efforts taking the shape of preventive, promotional, curative, and rehabilitative measures.

The long-term impacts of the COVID-19 pandemic in Indonesia have placed a tremendous load on the country's health-care system, including nurses. Nurses who work to combat COVID-19 are frequently under pressure [4]. This pandemic might generate stress for nurses due to its high prevalence and duration. The previous study reported that $50.4 \%$ (634 individuals) of 1830 respondents (nurses, doctors, and people who work in hospitals) reported experiencing depression, $44.6 \%$ (560 people) reported feeling nervous, and $34 \%$ (427 people) reported experiencing insomnia [5]. Patients visits and bed occupying rate grow, while the number of nurses remains unchanged during the COVID-19 pandemic [6]. The most evident concern is to nurse health workers' safety, especially those on the front lines who are more susceptible to COVID-19 exposure and hence life safety. The government has taken steps to reduce the risk of infection among nurses, such as setting working hours, providing lodging, and providing personal protective equipment, but the pandemic has caused work fatigue and burnout.

Burnout syndrome is a disorder in which individuals experience physical, mental, and emotional weariness as a result of prolonged exposure to 
stressful events requiring a high level of emotional involvement [7]. Burnout causes diminished motivation to study, negative attitudes, dissatisfaction, feelings of rejection by the environment, failure, and low self-esteem [8]. The high stresses caused by the consequences of transmission of the COVID-19 put nurses at risk of developing burnout syndrome [7]. The risk of burnout syndrome also impacts the immune system decrease of medical staff [9]. In Indonesia, nurses are assigned to work in the COVID-19 isolation room for $8 \mathrm{~h}$ each shift, with the morning shift beginning at 6 a.m. and the evening shift ending at 6 p.m. As the number of medical workers infected with COVID-19 rises, the workload of nursing staff that is not affected will grow due to the cascading effect, which results in double shifts observed that nurse practitioners and other medical professionals in Indonesia who performed frontline medical tasks during the COVID-19 outbreak had a 2-fold increased chance of developing burnout syndrome [10].

Acute stress from a pandemic impacts the whole community. Individuals working during the epidemic, on the other hand, are more stressed and have a harder time maintaining their health. Therefore, the mental health state of nurses who offer service during the COVID-19 pandemic is crucial, as it could impact their ability to properly fulfill their duties throughout the pandemic [11]. The previous study has been reported the burnout syndrome among nurses during early pandemic [10]. However, little of information was conducted to explore burnout among nurses and its impact on their mental health status among nurses in Indonesia during the second wave of COVID-19 pandemic in Indonesia. Understanding how nurse experienced burnout and what is the impact on their mental health is very important to inform health-care policy and nursing management on maintaining nurse mental well-being and prevent from nurse shortage. Moreover, findings of this study could be used to design a strategy to prepare for future pandemic. The purpose of this study was to evaluate the level of anxiety and burnout experienced by nurses during the COVID-19 pandemic.

\section{Methods}

\section{Study design}

This study was conducted using a crosssectional design. An online web-based survey was used to collected data in the national sample of nurses from 34 provinces across Indonesia from April to July 2021 (during the second wave of COVID-19 pandemic in Indonesia). The number of nurses in all provinces around Indonesia estimated about 345,508 [3].

\section{Sample}

Respondents are Indonesian nurses. To be considered for inclusion, each applicant must fulfill the following requirements: Registered nurses, aged over 18 years old, working in both public and private hospitals throughout Indonesia, working in emergency rooms, intensive care units, and specific rooms for handling complex patients. The sample size was determined using a power analysis, with power equal to 0.80 , alpha equal to 0.05 , and a moderate effect size. The required sample size was 120 . The total number of participants in this study was 243 (with a response rate of $78.6 \%$ ). The sample of this study consists of nurses from 34 provinces around Indonesia with range number of nurses for each province was 30-40 nurses. This study used a convenience sampling technique to select and recruited participants.

\section{Instrument}

This study used a questionnaire on nurse characteristics, such as age, gender, marital status, religion, duration of employment as a nurse, final education, work unit, and residence. Residence was asked their province, however, in our data analysis, we categorized nurses' residence into Java and Madura Island and out of Java and Madura Island. Since there were many provinces located in different Island of Indonesia. The Hamilton Anxiety Rating Scale (HAM-A) and the Maslach Burnout Inventory (MBI) were also employed.

The HAM-A questionnaire consists of 14 items that are used to determine levels of anxiety associated with workload and other factors. The HAM-A questionnaire is available in Indonesian and has a Cronbach's alpha of 0.756 [12].

The $\mathrm{MBI}$ is a 22-item questionnaire divided into three subscales: Emotional exhaustion (seven items), depersonalization (seven items), and personal accomplishment (seven items) (eight items). Each item is graded on a Likert scale, and a cumulative score of 67 or more indicates serious burnout on the component. This questionnaire is available in Indonesian and has a Cronbach's alpha of 0.87 [13].

\section{Data collection}

Ethical approval from the ethics committee of affiliated university was obtained (E.678/III/2021). Research questions were distributed to the hospital nursing managers of the COVID-19 epidemic by e-mail and were guaranteed to be engaged by nursing staff in their facilities. Participation was voluntary, and data were kept private. The participants were not required to provide any private information. The questionnaire was closed for 2 weeks after it is distributed. 


\section{Data analysis}

Descriptive statistics were used to determine the mean and standard deviation, as well as the percentages. The Kolmogorov-Smirnov and ShapiroWilk tests were used to determine whether the data had a normal distribution. Independent sample t-test was utilized for comparisons of independent two groups in cases when normally distributed data are involved. The Mann-Whitney U-test was employed for comparing two groups in which data did not follow a normal distribution. In addition, multiple linear regressions were used to determine characteristics associated with burnout. The study concluded that in all cases, tests had two outcomes, and $p<0.05$ was statistically significant. The study's data were analyzed using SPSS 24.0 (IBM Corporation, New York, USA).

\section{Results}

The sociodemographic characteristics of the participants are shown in Table 1. The participants' average age was 34.62 years (SD $=7.91)$. Nearly all of them (96.3\%) were Muslim, all of them (94.4\%) were married, and almost all of them (86.8\%) lived in Java and Madura Island. It was shown that $55.97 \%$ of respondents had worked in COVID-19 wards and had worked for an average of 11.77 years $(S D=8.24)$. Almost half of them have a confirmed diagnosis of COVID-19.

Table 1: Demographic characteristics $(n=243)$

\begin{tabular}{ll}
\hline Variables & $\mathrm{n}(\%)$ \\
\hline Age (years), Mean \pm SD & $34.62 \pm 7.91$ \\
Gender & \\
$\quad$ Male & $58(23.9)$ \\
$\quad$ Female & $185(76.1)$ \\
Marital status & $180(74.1)$ \\
$\quad$ Married & $63(25.9)$ \\
$\quad$ Unmarried & \\
Education & $114(46.9)$ \\
$\quad$ Diploma III & $129(53.1)$ \\
$\quad$ Bachelor & \\
Religion & $234(96.3)$ \\
$\quad$ Muslim & $9(3.7)$ \\
$\quad$ Non-Muslim & \\
Residence & $211(86.8)$ \\
$\quad$ Java and Madura Island & $32(13.2)$ \\
$\quad$ Out of Java and Madura Island & $107(44.03)$ \\
Working unit & $136(55.97)$ \\
$\quad$ Critical care unit & $11.77 \pm 8.24$ \\
$\quad$ COVID-19 wards & \\
$\quad$ Working experience (year), Mean $\pm S D$ & $124(49.0)$ \\
History of confirmed COVID-19 & $124(51.0)$ \\
$\quad$ Yes & \\
$\quad$ No &
\end{tabular}

The averages and standard deviations derived from the scales are shown in Table 2. The mean Hamilton Rating Scale Anxiety score for all subjects was 7.89 $(S D=2.94)$. The mean score of emotional exhaustion was 14.35 ( $S D=7.72)$, the depersonalization means score was 8.81 (SD = 5.11), and the professional accomplishment mean score was 13.51 (SD = 7.51).

Table 3 shows a comparison of the mean scale scores with the characteristics of the participants. There was no statistically significant difference between
Table 2: Distribution of means and standard deviations obtained from scales $(n=243)$

\begin{tabular}{lll}
\hline Variables & Mean \pm SD & Range \\
\hline Burnout & $14.35 \pm 7.72$ & \\
Emotional exhaustion & $8.81 \pm 5.11$ & $1-40$ \\
Depersonalization & $13.51 \pm 7.51$ & $0-25$ \\
Professional accomplishment & $7.98 \pm 2.94$ & $0-35$ \\
Hamilton Rating Scale Anxiety & & $0-51$ \\
\hline
\end{tabular}

the mean Hamilton Rating Scale Anxiety scores of the participants based on their age, gender, marital status, education, religion, resident area, working unit and experience, or history of confirmed COVID-19 ( $p>0.05)$ in the participants' mean scores. It was determined that there was no statistically significant difference in mean scores from the $\mathrm{MBI}$ emotional exhaustion subdimension among individuals based on age, gender, marital status, religion, resident area, working unit, and history of confirmed COVID-19 ( $p>0.05)$. Nurses with a high school diploma and more work experience reported greater emotional exhaustion $(p<0.05)$. When the participants' mean $\mathrm{MBI}$ depersonalization scores were compared, no significant differences in terms of age, gender, marital status, education, religion, resident area, work unit, and history of confirmed COVID-19 were observed $(p>0.05)$. Nurses with a longer period of working experience were more desensitized $(p<0.05)$ than those with a shorter period of experience. There was no significant difference in age, gender, marital status, education, religion, residence area, working unit, or history of confirmed COVID-19 ( $p>0.05$ ). Nurses with a bachelor's degree felt insufficiently qualified to provide nursing care $(p<0.05)$

Education and job experience had a substantial effect on the $\mathrm{MBI}$ emotional exhaustion and depersonalization, with $\mathrm{R}^{2}$ values of $10.8 \%$ and $18.5 \%$, respectively. When anxiety was included in the model, the $\mathrm{R}^{2}$ for emotional exhaustion increased to $20.4 \%$ and the $\mathrm{R}^{2}$ for depersonalization increased to $22.2 \%$, respectively. Work experience had a little effect on the MBl's professional accomplishment $\left(R^{2}=10.3 \%\right)$ but had a much larger effect when the variable of anxiety was included in the model $\left(R^{2}=18.3 \%\right)$ (Table 4).

\section{Discussion}

The study focuses on the anxiety and burnout experienced by nurses caring for patients during the COVID-19 epidemic, particularly during the second wave. This study revealed that during the COVID-19 epidemic, nurses experienced many emotional states, including exhaustion, depersonalization, and anxiety. Our findings are in line with earlier research that found that nurses who care for people with contagious diseases are more likely to be burned out. To be more specific, their emotional exhaustion and depersonalization ratings are higher than those of 
Table 3: Comparison of the mean scale scores with the participants' characteristics $(n=243)$

\begin{tabular}{|c|c|c|c|c|c|c|c|c|}
\hline \multirow[t]{2}{*}{ Variables } & \multicolumn{2}{|c|}{ Hamilton Rating Scale Anxiety } & \multicolumn{2}{|c|}{ Emotional exhaustion } & \multicolumn{2}{|c|}{ Depersonalization } & \multicolumn{2}{|c|}{ Professional accomplishment } \\
\hline & Mean \pm SD & $\mathrm{p}$-value & Mean \pm SD & $\mathrm{p}$-value & Mean \pm SD & $p$-value & Mean \pm SD & $p$-value \\
\hline Age, Mean \pm SD & & $0.539^{\mathrm{a}}$ & & $0.121^{\mathrm{a}}$ & & $0.127^{\mathrm{a}}$ & & $0.059^{\mathrm{a}}$ \\
\hline \multicolumn{9}{|l|}{ Gender } \\
\hline Male & $7.97 \pm 3.46$ & 0.986 & $16.36 \pm 8.13$ & 0.023 & $9.66 \pm 5.16$ & 0.151 & $14.66 \pm 8.05$ & 0.186 \\
\hline Female & $7.99 \pm 3.11$ & & $13.72 \pm 97.51$ & & $8.55 \pm 5.08$ & & $13.16 \pm 7.32$ & \\
\hline \multicolumn{9}{|l|}{ Marital status } \\
\hline Married & $8.00 \pm 4.85$ & 0.969 & $14.43 \pm 7.41$ & 0.992 & $8.73 \pm 5.16$ & 0.513 & $13.43 \pm 7.87$ & 0.519 \\
\hline Unmarried & $7.95 \pm 9.09$ & & $14.42 \pm 8.84$ & & $9.25 \pm 5.09$ & & $14.18 \pm 6.47$ & \\
\hline \multicolumn{9}{|l|}{ Education } \\
\hline Diploma III & $7.02 \pm 8.08$ & 0.120 & $12.14 \pm 6.38$ & 0.000 & $8.09 \pm 4.73$ & 0.078 & $11.97 \pm 6.54$ & 0.005 \\
\hline Bachelor & $8.60 \pm 9.65$ & & $15.95 \pm 8.31$ & & $9.28 \pm 5.36$ & & $14.74 \pm 8.04$ & \\
\hline \multicolumn{9}{|l|}{ Religion } \\
\hline Muslim & $8.02 \pm 4.02$ & 0.278 & $14.32 \pm 7.67$ & 0.375 & $8.75 \pm 5.02$ & 0.495 & $13.49 \pm 7.48$ & 0.281 \\
\hline Non-Muslim & $4.00 \pm 4.34$ & & $11.50 \pm 7.20$ & & $7.33 \pm 5.13$ & & $10.17 \pm 4.88$ & \\
\hline \multicolumn{9}{|l|}{ Residence } \\
\hline Java and Madura Island & $8.39 \pm 3.29$ & 0.127 & $14.46 \pm 7.74$ & 0.894 & $8.80 \pm 5.81$ & 0.993 & $13.62 \pm 7.53$ & 0.635 \\
\hline Out of Java and Madura Island & $7.00 \pm 3.39$ & & $14.00 \pm 6.36$ & & $8.82 \pm 5.07$ & & $12.00 \pm 8.16$ & \\
\hline \multicolumn{9}{|l|}{ Working unit } \\
\hline Critical care unit & $8.29 \pm 3.35$ & 0.637 & $15.04 \pm 7.41$ & 0.222 & $9.49 \pm 4.82$ & 0.069 & $14.27 \pm 7.08$ & 0.164 \\
\hline COVID-19 wards & $7.74 \pm 2.40$ & & $13.82 \pm 7.95$ & & $8.29 \pm 5.28$ & & $12.92 \pm 7.81$ & \\
\hline Working experience & & $0.059^{\mathrm{a}}$ & & $0.021^{\mathrm{a}}$ & & $0.049^{\mathrm{a}}$ & & $0.057^{\mathrm{a}}$ \\
\hline \multicolumn{9}{|l|}{ History of confirmed COVID-19 } \\
\hline Yes & $8.03 \pm 8.35$ & 0.931 & $14.28 \pm 7.86$ & 0.883 & $13.66 \pm 5.38$ & 0.238 & $13.37 \pm 7.68$ & 0.762 \\
\hline No & $7.93 \pm 3.56$ & & $14.43 \pm 7.62$ & & $13.37 \pm 4.83$ & & $13.66 \pm 7.35$ & \\
\hline
\end{tabular}

Table 4: Factors associated with burnout among nurses $(n=243)$

\begin{tabular}{|c|c|c|c|c|c|c|}
\hline \multirow[t]{2}{*}{ Variables } & \multicolumn{2}{|c|}{ Emotional exhaustion } & \multicolumn{2}{|c|}{ Depersonalization } & \multicolumn{2}{|c|}{ Professional accomplishment } \\
\hline & $\mathrm{B}(\mathrm{SE})$ & $\mathrm{p}$-value & $\mathrm{B}(\mathrm{SE})$ & $\mathrm{p}$-value & $\mathrm{B}(\mathrm{SE})$ & $\mathrm{p}$-value \\
\hline Gender (male vs. female) & $-0.578(0.796)$ & 0.469 & $-0.701(1.158)$ & 0.545 & $0.501(1.417)$ & 0.724 \\
\hline Education (diploma III vs. bachelor) & $1.076(0.574)$ & 0.032 & $1.933(0.836$ & 0.022 & $1.637(1.023)$ & 0.111 \\
\hline Working experience & $-0.078(0.043)$ & 0.041 & $-0.140(0.058)$ & 0.018 & $-0.164(0.077)$ & 0.034 \\
\hline $\mathrm{R}^{2}$ & 0.108 & & 0.185 & & 0.107 & 0.103 \\
\hline Anxiety & $0.216(0.034)$ & $<0.001$ & $0.317(0.049)$ & $<0.001$ & $0.289(0.078)$ & $<0.001$ \\
\hline $\mathrm{R}^{2}$ & 0.204 & & 0.222 & & 0.242 & 0.183 \\
\hline
\end{tabular}

Bold: Significant $(\mathrm{p}<0.05)$.

personnel who do not provide care to patients suffering from infectious diseases [14], [15]. A detailed plan for infection surveillance is strongly recommended, as well as hospital facilities and employees. Managers must devote time and attention to the health of their staff nurses. Furthermore, long-term measures for workplace hygiene, minimizing shifts, and identifying stresses are required to manage both present epidemics and potential pandemics.

Individuals' anxiety levels are affected by protracted periods of uncertainty in unexpected situations such as disasters and/or pandemics. The research reveals that nurse experienced anxiety among individuals during the COVID-19 pandemic. Several studies have found that the symptoms of anxiety are more prevalent in health-care professionals compared with the general population [16], [17], [18]. During the COVID-19 epidemic, nurses typically live separated in separate locations to avoid infecting their relatives/ families [19]. This circumstance is likely to have a detrimental effect on nurses' psychosocial well-being.

Nurses with a bachelor's degree and more work experience had a higher burnout syndrome score. Nurses' burnout was found to be higher when they had a higher educational level [20], [21] and a higher degree [16]. A meta-analysis [22] of 57 research concluded that clinical experience should be considered when inferring more valid conclusions about nurse burnout. Specific training related to COVID-19 is in need of emphasis because to the lack of understanding, safety precautions, and protective equipment. The 2009 pandemic (H1N1) [23] and the SARS outbreak [24] highlight nurses' concerns about insufficient training and experience in dealing with difficult health-care situations. As a result of this extreme condition, nurses must get new knowledge and abilities concerning COVID-19 to feel more confident in their ability to provide health-care services to patients. Nurses who have received adequate training may increase their self-efficacy, which is crucial when confronted with disasters such as pandemics [25].

The burnout and anxiety of the frontline nurses have been associated. Nurses who were diagnosed with anxiety and depression had more burnout than those without mental illness, which supported Hardy et al.'s findings but differed from it in one key respect: They also had a lower chance of being burned out when they were suffering with anxiety and depression [26]. The findings above indicated that there was a certain level of concern among nurses throughout the COVID-19 period, which had a stronger impact on burnout. In other words, the greater the severity of psychological symptoms (depression, anxiety, and perceived stress), the greater the amount of burnout [27], which is consistent with current study findings. Burnout among nurses may have a detrimental effect on their mental health. Self-control and emotional regulation can be used to solve problems and alleviate anxiety in a timely and effective manner [6]. To fight and prevent burnout, individuals should rely on others for emotional support and consult mental health specialists [28], [29]. Furthermore, rest, healthy eating, appropriate physical activity, time for personal pursuits, and taking time off to unwind are among the many measures which might 
stave off chronic stress and burnout [28], [29]. Given the high rate of occupational burnout among nurses throughout the COVID-19 period, clinical intervention can be carried out from this standpoint.

\section{Study limitation}

The limited sample size of our study could have a significant impact on generalizability. The study's cross-sectional design means that association, not causation, can be deduced. A longitudinal design should be considered for future studies. Another limitation is that self-selection bias could possibly have an impact on the generalizability of the outcomes of the study. The research data were obtained during the second wave of the COVID-19 epidemic in Indonesia, thus adequate time should elapse for anxiety and burnout symptoms to emerge. Future research should be conducted in Indonesia using mixed method study to compare anxiety and burnout levels between the initial and secondary waves of the COVID-19 pandemic, with nurses who have been caring for patients exposed to COVID-19.

\section{Conclusion}

The study examined the anxiety and burnout experienced by nurses during COVID-19. Given the length of the pandemic, it is critical to recognize this deterioration in nurses. This COVID-19 pandemic presents a major problem for nurses everywhere, and by understanding the lessons learned from the second wave, effective strategies for the succeeding waves can be put in place. Intervention needs to be designed and implemented soon to prevent shortage of nurse due to high level of burnout syndrome. Efforts should be made by governments and policymakers in this regard in better preparing health-care systems, persons, and nursing to respond to the COVID-19 pandemic in the future.

\section{References}

1. Pan A, Liu L, Wang C, Guo H, Hao X, Wang Q, et al. Association of Public Health Interventions With the Epidemiology of the COVID-19 Outbreak in Wuhan, China. JAMA. 2020;323(19):1915-23. http://doi.org/10.1001/jama.2020.6130 PMid:32275295

2. International Council of Nurses. ICN Confirms 1,500 Nurses Have Died from COVID-19 in 44 Countries and Estimates that Healthcare Worker COVID-19 Fatalities Worldwide Could be More Than 20,000; 2020. Available from: https://www. icn.ch/news/icn-confirms-1500-nurses-have-died-covid-19- 44-countries-and-estimates-healthcare-worker-covid. [Last accessed on 2021 Mar 24].

3. Ministry of Health. Data of COVID-19 and Nurses; 2021 Available from: https://www.kemkes.go.id/index.php?lg=LN02. [Last accessed on $2021 \mathrm{Mar}$ 24].

4. Mo Y, Deng L, Zhang L, Lang Q, Liao C, Wang N, et al. Work stress among Chinese nurses to support Wuhan in fighting against COVID-19 epidemic. J Nurs Manage. 2020;28(5):1002-9. http:// doi.org/10.1111/jonm.13014

PMid:32255222

5. Lai J, Ma S, Wang Y, Cai Z, Hu J, Wei N, et al. Factors associated with mental health outcomes among health care workers exposed to coronavirus disease 2019. JAMA Netw Open. 2020;3(3):e203976. http://doi.org/10.1001/ jamanetworkopen.2020.3976

PMid:32202646

6. Ilyas N, Azuine RE, Tamiz A. COVID-19 Pandemic in Pakistan Int J Transl Med Res Public Health. 2020;4(1):37-49.

7. Maslach $\mathrm{C}$, Jackson S, Leiter M. The maslach burnout inventory manual. In: Evaluating Stress: A Book of Resources. United States: Scarecrow Press, Inc.; 1997. p. 191-218.

8. Adawiyah RA. Kecerdasan emosional, dukungan sosial dan Kecenderungan Burnout. Pers Psikol Indones. 2013;2(2):99-107.

9. Lailani F. Burnout pada perawat ditinjau dari efikasi diri dan dukungan sosial di Rumah Sakit "XYZ" Di Surakarta. J Talent Psikol. 2014;3(1):20-35.

10. Soemarko D. Bournout Kelelahan Kerja Pada Tenaga Medis di Ruang isolasi Covid 19 Rumah Sakit Ciptomangunkusumo. Jakarta: Bulletin Jakarta; 2020.

11. Zhu $\mathrm{H}$, Wang L, Fang $\mathrm{C}$, Peng $\mathrm{S}$, Zhang L, Chang $\mathrm{G}$, et al Clinical analysis of 10 neonates born to mothers with 2019nCoV pneumonia. TransI Pediatr. 2020;9(1):51-60. http://doi. org/10.21037/tp.2020.02.06

PMid:32154135

12. Muhamad Ramdan I. Reliability and validity test of the Indonesian version of the hamilton anxiety rating scale (HAM-A) to measure work-related stress in nursing. J Ners. 2019;14:33.

13. Sudrajat DA, Indrianti TO, Supriatin E, Hayati SN, Lindayani L. Nurse burnout: Comparing public and private hospitals in Indonesia. Br J Healthc Manag. 2021;27(2):1-7. https://doi. org/10.12968/bjhc.2019.0090

14. Boo YL, Liam CC, Lim SY, Look ML, Tan MH, Ching SM, et al. Stress and burnout syndrome in health-care providers treating dengue infection: A cross-sectional study. Med J Malaysia. 2018;73(6):371-5.

PMid:30647206

15. Qiao Z, Chen L, Chen M, Guan X, Wang L, Jiao $Y$, et al. Prevalence and factors associated with occupational burnout among HIVIAIDS healthcare workers in China: A crosssectional study. BMC Public Health. 2016;16(1):335. https://doi. org/10.1186/s12889-016-2890-7

PMid:27079376

16. Zhang $\mathrm{Y}$, Wang $\mathrm{C}$, Pan W, Zheng J, Gao J, Huang X, et al Stress, Burnout, and Coping Strategies of Frontline Nurses During the COVID-19 Epidemic in Wuhan and Shanghai, China. Front Psychiatry. 2020;11:565520. https://doi.org/10.3389/ fpsyt.2020.565520

PMid:33192686

17. Pappa S, Ntella V, Giannakas T, Giannakoulis VG, Papoutsi E, Katsaounou P. Prevalence of depression, anxiety, and insomnia among healthcare workers during the COVID-19 pandemic: A systematic review and meta-analysis. Brain Behav Immun. 2020;88:901-7. https://doi.org/10.1016/j.bbi.2020.05.026. PMid:32437915

18. Liu Q, Shen D, Chen S, Liu J. Supporting frontline nurses during 
the fight against COVID-19. J Am Psychiatric Nurs Assoc. 2020;26(6):525-6. https://doi.org/10.1177/1078390320946825 PMid:32787545

19. Woo T, Ho R, Tang A, Tam W. Global prevalence of burnout symptoms among nurses: A systematic review and metaanalysis. J Psychiatr Res. 2020;123:9-20.

20. Hu D, Kong $Y$, Li W, Han Q, Zhang X, Zhu LX, et al. Frontline nurses' burnout, anxiety, depression, and fear statuses and their associated factors during the COVID-19 outbreak in Wuhan, China: A large-scale cross-sectional study. EClinicalMedicine. 2020;24:100424. https://doi.org/10.1016/j.eclinm.2020.100424 PMid:32766539

21. Sayilan A, Kulakaç N, Uzun S. Burnout levels and sleep quality of COVID-19 heroes. Perspect Psychiatr Care. 2020;57(3):12316. https://doi.org/10.1111/ppc.12678 PMid:33145787

22. Pradas-Hernández L, Ariza T, Gómez-Urquiza JL, AlbendínGarcía L, De la Fuente El, Cañadas-De la Fuente GA. Prevalence of burnout in paediatric nurses: A systematic review and meta-analysis. PLoS One. 2018;13(4):e0195039. https:// doi.org/10.1371/journal.pone.0195039 PMid:29694375

23. Imai $\mathrm{H}$, Matsuishi $\mathrm{K}$, Ito A, Mouri K, Kitamura N, Akimoto K, et al. Factors associated with motivation and hesitation to work among health professionals during a public crisis: A cross sectional study of hospital workers in Japan during the pandemic (H1N1) 2009. BMC Public Health. 2010;10(1):672. https://doi. org/10.1186/1471-2458-10-672

PMid:21050482
24. Liu X, Kakade M, Fuller CJ, Fan B, Fang Y, Kong J, et al Depression after exposure to stressful events: Lessons learned from the severe acute respiratory syndrome epidemic. Compr Psychiatry. 2012;53(1):15-23. https://doi.org/10.1016/j. comppsych.2011.02.003

\section{PMid:21489421}

25. Kılıç N, Şimşek N. The effects of psychological first aid training on disaster preparedness perception and self-efficacy. Nurse Educ Today. 2019;83:104203. https://doi.org/10.1016/j. nedt.2019.104203

PMid:31683114

26. Chen J, Li J, Cao B, Wang F, Luo L, Xu J. Mediating effects of self-efficacy, coping, burnout, and social support between job stress and mental health among young Chinese nurses. J Adv Nurs. 2020;76(1):163-73.

27. Papathanasiou IV, Tsaras K, Kleisiaris CF, Fradelos EC TsaloglidouA, Damigos D.Anxiety and depression in staff ofmental units: The role of Burnout. Adv Exp Med Biol. 2017;98:7185-97. https://doi.org/10.1007/978-3-319-57379-3_17

28. Hardy P, Costemale-Lacoste JF, Trichard C. Comparison of burnout, anxiety and depressive syndromes in hospital psychiatrists and other physicians: Results from the ESTEM study. Psychiatry Res. 2019;284:112662. https://doi. org/10.1016/j.psychres.2019.112662 PMid:31703985

29. Svmrisaah S. The relationship. Between Burnout dimensions and psychological symptoms (depression, anxiety and stress) among nurses. J Holistic Nurs Midwif. 2017;27:37-43. https:// doi.org/10.18869/acadpub.hnmj.27.2.37 